\title{
FOOD LABELING U.K. TARGETS SOME GENE-MODIFIED FOODS
}

LONDON - British manufacturers are now being asked to label certain foods as products of gene technology. No other European country has yet acted in this way, and labeling is not included in the novel foods directive now being finalized by the European Commission.

The new requirements, which are designed to help consumers, come in the form of guidelines from the government's Food Advisory Committee (FAC). Although lacking the force of law, these state that the words "contains products of gene technology" should be incorporated in labels for two categories: foodstuffs derived from organisms modified to contain genes "from sources outside their own species"; and novel foods derived from genetically modified organisms (GMOs) which do not contain the cells or DNA of that organism, but which differ from conventional products traditionally consumed in Western Europe. Two other categories are exempt from labeling. They include most foodstuffs from GMOs involving intraspecies gene transfers and most foods that do not contain the cells or DNA of the GMO and which are "nature identical" with products traditionally consumed in Europe.

Introduction of the guidelines has been hastened by the furor over the permission given by the Ministry of Agriculture, Fisheries and Foods to a U.K. subsidiary of the Dutch company Gist-brocades (Delft) for largescale manufacture of a genetically engineered baker's yeast (Bio/ Technology 8:281, Apr. '90). Public interest groups that complained about undue secrecy surrounding that announcement are now dissatisfied with exemptions in the new guidelines. "Consumers have a right to know in all cases when gene technology has been used in food manufacture," says Julie Hill of the Green Alliance. Tim Laing, director of Parents for Safe Food, agrees. "There is no logical case for the four different categories. Commercial companies always resist labeling, but for the moment every food item manufactured in this way ought to be identifiable, even if some labeling can be phased out later in the light of public acceptance and our growing experience of safety."

One company to be affected by the new guidelines is ICI (London), which has developed transgenic tomatoes expressing an antisense mRNA designed to block polygalacturonase production and thus reduce softening during storage. "ICI supports food labeling that is scientifically sound and provides the consumer with meaningful information," says company spokesperson Nicky Philipps. "In this case, we feel that the proposed labeling could confuse rather than help consumers. We are also concerned, in the absence of legal enforcement, that imported foods will not have to be labeled." ICI will be asking the Ministry to reconsider the guidelines accordingly.

"It should not be assumed that the labeling advice for each of the four categories would automatically apply in every case," the FAC says. "The Committee wishes to consider the labeling requirements for such foods on a case-by-case basis, and as a consequence these guidelines may need to be revised."

-Bernard Dixon

\section{From Contract Research...}

\section{DNA Cloning \\ Expression in Pro- and Eucaryotic Cells \\ Sequencing of DNA \\ Purification and Characterization of Proteins \\ Analysis of Carbohydrates \\ Determination of Contaminants via PCR, ELISA etc.}

Validated Standard Operating Procedures

Documentation for Registration

\section{...To Analytical Services}

Gesellschaft zur

biotechnologischen

Entwicklung

von Pharmaka mbH
Czernyring 22

D-6900 Heidelberg 1

Phone: + $49622114024-26$

Fax: + 496221163574 